\title{
Nano-core effect in nano-engineered cementitious composites
}

\author{
Baoguo Han ${ }^{1, *}$, Liqing Zhang ${ }^{1}$, Shuzhu Zeng ${ }^{1}$, Sufen Dong ${ }^{1}$, Xun $\mathrm{Yu}^{2,3}$, Rongwei Yang ${ }^{4}$, Jinping $\mathrm{Ou}^{1,5}$
}

\begin{abstract}
Nanoscale impact can bring big changes in micro-meso-macroscale behaviors of the composites. addition of nano fillers makes cementitious materials stronger, more durable and multifunctional/smart. This paper aims at investigating the underlying mechanism for understanding and controlling the nano-engineered cementitious composites. The nano-core effect is proposed through integrating core-effect with nano effect, and is proved by experimental evidences for the cementitious composites with different nano fillers. The nano-core effect is closely relative to the intrinsic properties of nano fillers, composition and processing of the cementitious composites. The behaviors of the nano-engineered cementitious composites are governed by nano-core effect zone, i.e. nano-core-shell element. It is therefore concluded that the nano-core effect is fundamental for design, fabrication and application of the nano-engineered cementitious composites.
\end{abstract}

Key words: A. Reinforced cement/plaster; A. Smart materials; B. Physical properties; B. Microstructures

\section{Introduction}

Cementitious composites are the most widely used materials for infrastructures because they are resistant to water, easily formed into various shapes and sizes, cheap and readily available everywhere. Twice as much cementitious composites are used in infrastructures around the world 
than the total of all other building materials, including wood, steel, plastic and aluminum. In the foreseeable future, cementitious composites will continue to play an important role in infrastructure construction. However, the development of cementitious composites is encountering enormous problems and challenges. Firstly, cement manufacturing has a direct and visible impact on the world's resources, energy consumption and environment. Making one ton of cement requires about 2 tons of raw material (limestone and shale), consumes about $4 \mathrm{GJ}$ of energy in electricity, process heat, and transport (the energy equivalent to 131 cubic meters of natural gas), produces approximately one ton of $\mathrm{CO}_{2}$ produces about $3 \mathrm{~kg}$ of $\mathrm{NO}_{\mathrm{X}}$ (an air contaminant that contributes to ground-level smog), and produces about $0.4 \mathrm{~kg}$ of PM10 (an airborne particulate matter that is harmful to the respiratory tract when inhaled). Secondly, increasing attention has been paid on the security of infrastructures since cementitious composites are brittle material and usually work with cracks. Thirdly, the durability of infrastructures is a very important issue, in particular during the process of their design and application. Fourthly, cementitious composites are complex composites in nature. Fifthly, the multifunctional and smart cementitious composites are required since traditional cementitious composites that just serve as structural materials cannot meet the requirement of the safety, longevity and function of advanced engineering infrastructures. Nanotechnology is an emerging field related to the understanding and control of matters at nanoscale. Nanomaterials have remarkable properties and functions which can endow cementitious composites high-performances (including high mechanical property and durability) and multifunctionality/intelligence. Therefore, applications and advances of nanotechnology and nanomaterials have injected new vitality into cementitious composites [1-5]. Nano nonmetallic oxide and metallic oxide similar to cementitious composition are first used to enhance/modify cementitious materials. The big gains in mechanical, durable and functional properties were achieved. An addition of 1.5\% nano-sillica (NS) increased the $3 \mathrm{~d}$ compressive and flexural 
strengths by $45.6 \%$ and $18.4 \%$, respectively [6]. Meanwhile, the addition of NS can increase the freeze-thaw resistance, chloride penetration and permeability, abrasion resistance and fire resistance of cementitious composites [7-10]. The fracture toughness of cementitious composites can be enhanced by $400 \%$ when nano- $\mathrm{ZrO}_{2}$ is used as fillers [11]. An addition of $5 \%$ nano- $\mathrm{Al}_{2} \mathrm{O}_{3}$ can increase the elasticity modulus of cementitious composites by $143 \%$ [12]. The electrical resistance of cementitious composites can be decreased by $45 \%$ with $5 \%$ nano- $\mathrm{Fe}_{2} \mathrm{O}_{3}[12]$. Nano- $\mathrm{TiO}_{2}$ can endow cementitious materials with the photocatalytic effect to decompose both organic pollutants and oxides such as $\mathrm{NO}, \mathrm{NO}_{2}$ and $\mathrm{SO}_{2}$ [13]. Moreover, extensive research endeavors demonstrated the potential of various nano carbon materials including carbon nanotubes (CNTs), carbon nanofibers (CNFs), and graphene for enhancing/modifying cementitious materials [14-22]. The observed best performance enhancement of cementitious with CNTs or CNFs include a 300\% increase in compressive strength, a $34.28 \%$ increase in tensile strength, a $269 \%$ increase in flexural strength, a $270 \%$ increase in fracture toughness, a $14 \%$ increase in fracture energy, an over $600 \%$ improvement in Vickers's hardness at the early ages of hydration, a 2200\% increase in deflection, a $130 \%$ increase in ductility, an over $430 \%$ improvement in resilience and a $227 \%$ increase in Young's modulus [17]. Only $0.03 \%$ of graphene can improve the tensile, flexural and compressive strength of cementitious composites by $78.6 \%, 60.7 \%$ and $38.9 \%$, respectively [17]. The presence of CNTs obviously enhances the transport property and durability of cementitious materials [19]. Graphene significantly improves the moisture transport performance and acid resistance of the composites at 0.05 vol. $\%$ of dosage [17]. The electrical resistivity reduction extent of cementitious materials with 1.52 vol. \% of CNTs/nano carbon black composite filler is $99.9 \%$ [23]. The thermal conductivity of CNTs cementitious composites is $85 \%$ greater than that of cementitious composites without CNTs [24]. The damping capacity of cementitious composites with $2 \%$ CNTs is 1.6 times than that of cementitious composites without CNTs [25]. An addition of 0.6 wt. \% CNTs into 
cementitious materials can lead to a $27 \%$ decrease in electromagnetic wave reflectivity at a frequency of $2.9 \mathrm{GHz}$ [17]. Additionally, the composites with CNTs, CNFs or graphene feature smart self-sensing (e.g. sensing stress, strain, crack, damage, temperature, and smoke), self-heating and steel cathodic protection performances. Nano fillers not only can enhance/modify the above mentioned performances of cementitious composites in hardened state, but also have strong impact on the rheology and workability of fresh cementitious composites [24].

Although a lot of researches have been done on the behaviors of cementitious composites with nano fillers, the modification mechanism of nano fillers to the performances of cementitious materials remains elusive. Therefore, this paper will perform a fundamental research into the nano and micro-scale phenomena that govern the behaviors of cementitious composites with nano fillers. The nano-core effect in nano-engineered cementitious composites is firstly proposed, and it was proved by experimental evidences of cementitious composites with different nano fillers. The factors affecting nano-core effect are comprehensively analyzed. Finally, the concept of nano-core effect zone is proposed to link the nano-core effect to the behaviors of the nano-engineered cementitious composites.

\section{Materials and methods}

\subsection{Materials}

In this study, Portland cement (P.O 42.5R conforming to the requirement of Chinese standard) produced by Dalian Onoda Cement Co. Ltd. in China was used. Standard sand produced by Xiamen Ai Si Ou Standard Sand Co. Ltd., China was used as aggregate. Nano fillers include NS, Nano-TiO Nano- $\mathrm{ZrO}_{2}, \mathrm{CNFs}$, and multi-layer graphene (MLG). NS with mean particle size of $12 \mathrm{~nm}$ produced by Tokuyama in Japan was applied. Nano- $\mathrm{TiO}_{2}$ with mean particle size of $20 \mathrm{~nm}$ was purchased from Nanjing Haitai Nanomaterials Co., Ltd. in China. Nano- $\mathrm{ZrO}_{2}$ (average diameter $20 \mathrm{~nm}$, Nanjing Haitai Nanomaterials Co. Ltd. in China ) was used. CNFs (trade name PR-24-XT-HHT, 
average diameter $100 \mathrm{~nm}$, length on the order of 50-200 $\mu \mathrm{m}$ ) were procured from Pyrograf Products, Inc. an affiliate Applied Science, USA. The water reducing agent is polycarboxylate superplasticizer used to disperse nano fillers.

\subsection{Methods}

The process of fabricating nano-engineered cementitious composites is as follows: 1) Water, superplasticizer and nano fillers were mixed by glass bar and then sonicated to form a suspension; 2) Cement and aggregate were put into the suspension slowly in stir pan and mixed by agitator; 3) The mixture was poured into the oiled mould and the mould was put on the electric vibrator in order to eliminate bubbles; 4) All nano-engineered cementitious composites were cured at temperature of $20^{\circ} \mathrm{C}$ in $95 \%$ relative humidity for $24 \mathrm{~h}$ before demold. Then specimens were cured in water at $20 \pm 1^{\circ} \mathrm{C}$ until the curing age $[6,19]$. Three test specimens were fabricated for each cementitious material.

Field Emission Scanning Electron Microscope (Nova Nano SEM 450, American FEI Ltd.) was used to observe the microstructures. Thermogravimetry (TG) analysis was performed using a METTLER TOLEDO STARe system to get the hydration degree of cement [26]. The condition of TG analysis was under nitrogen atmosphere at a heating rate of $10^{\circ} \mathrm{C} / \mathrm{min}$ up to $1000^{\circ} \mathrm{C}$. X-Ray diffraction (XRD) (Bruker D8 Advance, Bruker German) was applied for studing the tendency of crystal of calcium hydroxide [27]. The quasi-steady-state method is applied to test thermal conductivity with ZKY-BRDR Quasi Steady State Specific Heat/Thermal Conductivity Coefficient Tester (Cheng Du Century Science and Technology Co., Ltd., China) in this experiment.

\section{Results and discussion}

3.1 Description of the nano-core effect

The nano-core effect means the combination of nano effect and core effect caused by nano fillers incorporated into cementitious composites. Due to the ultra high specific surface area and great 
surface energy, the hydration production will deposit on the nano fillers. Meanwhile, some of the nano fillers can react with the hydration production of cementitious material. Furthermore, thanks to the small size of nano fillers, numerous fillers are extensively distributed in the cementitious matrix. As a result, the nano fillers serve as nano-cores. As shown in Fig.1, the local area around nano-core features unique composition and structure, which are obviously different from that of the cementitious material without nano fillers and have strong effect on the macro-behaviors of the cementitious composites.

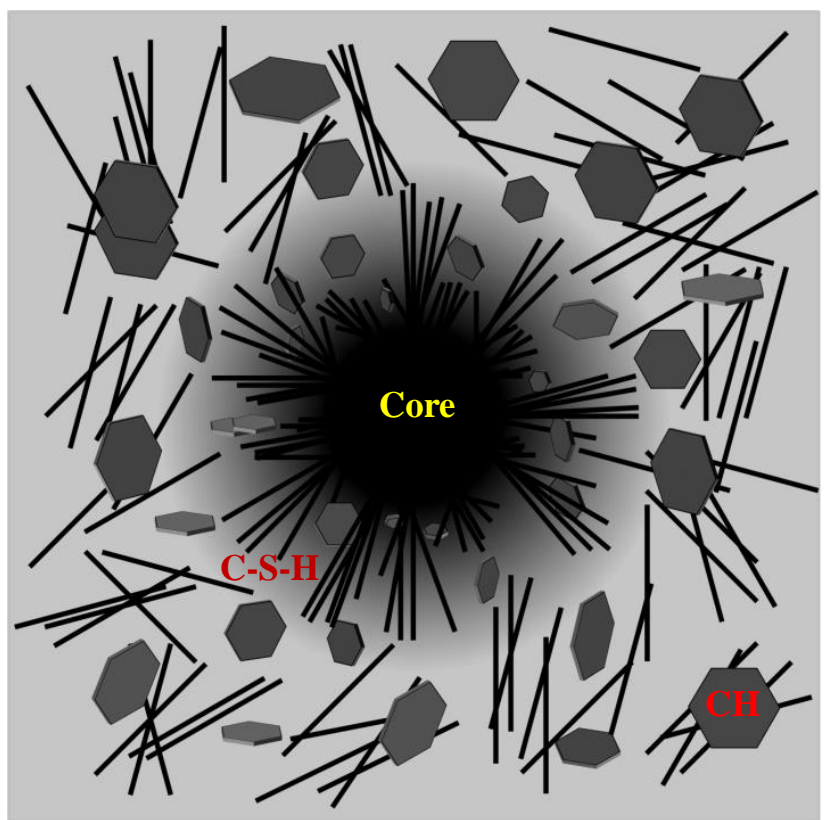

Fig. 1 - Diagram of the local area around nano-core inside cementitious composites

\subsubsection{Nano effect}

Nano-effect mainly results from the small size and high surface area of nano fillers.

\subsubsection{Small size}

The size of nano fillers in at least one orientation is less than $100 \mathrm{~nm}$. The nano fillers used in cementitious materials include nano nonmetallic oxides, nano metallic oxide, nano carbon materials and other nano materials. The size, volume of single nano particle, concentration in cementitious materials, and numbers of typical nano fillers in $1 \mathrm{~cm}^{3}$ cementitious composites are listed in Table 1, 
Table 2 and Table 3. As a contrast, the information of cement particle is also shown in Table 1. It should be noted that the numbers of nano fillers in $1 \mathrm{~cm}^{3}$ cementitious composites are calculated assuming that nano fillers are in ideal geometrical shape and exist in single particle. As shown in Table 1, Table 2 and Table 3, the numbers of 0.1 vol. $\%$ of nano fillers in $1 \mathrm{~cm}^{3}$ cementitious composites are in the range from $3.2 \times 10^{8}$ to $8.0 \times 10^{16}$. This means that numerous nano fillers exist in cementitious composites even at low filler concentration level, which is one of the foundations that a small amount of nano fillers can have huge effect on cementitious materials. Fig.2 shows SEM mapping images of cementitious composites with nano fillers. The white points in Fig. 2(a) and Fig. 2(b) are nano- $\mathrm{TiO}_{2}$ and nano- $\mathrm{ZrO}_{2}$, respectively, and the big black areas are the cement matrix. As can be seen from Fig. 2, the nano fillers form extensive distribution inside the cementitious composites.

In addition, some unique physical and chemical characteristics of nano fillers are derived from small size effect. For example, owing to more atoms in surface, NS features higher reaction activity against the silica fume, which is commonly used microscale mineral admixture for cementitious composites. When the diameter of the crystallites of a particle falls below a critical radius of about $10 \mathrm{~nm}$, each charge carrier appears to behave quantum mechanically. Therefore, $\mathrm{TiO}_{2}$ in the form of nanoparticles presents much more effective photocatalytic activity than that in bulk powder [28]. The strength of the $\mathrm{sp}^{2}$ carbon-carbon bonds endues CNTs amazing mechanical properties. The tensile strength and Young's modulus of CNTs are 20 times and 10 times that of microscale carbon fibers (CFs), respectively. The elongation at break of CNTs is $18 \%$, and is 18 times that of CFs. The electrons have fewer possibilities to scatter inside CNTs. This reduced scattering gives CNTs very high conductivity. CNTs can carry the highest current density of any known material, measured as high as $10^{9} \mathrm{~A} / \mathrm{cm}^{2}$. CNTs possess excellent field emission characteristics such as a low threshold field for emission and a high current density. The field mission has been observed at fields lower 
than $1 \mathrm{~V} / \mathrm{m}$, and high current densities of over $1 \mathrm{~A} / \mathrm{cm}^{2}$ have been obtained. CNTs have been shown to have a thermal conductivity at least twice of that of diamond. The hardness of graphene is more than $100 \mathrm{GPa}$ and harder than diamond. The strength of graphene is dozens of times stronger than that of steels. The coefficient of thermal conductivity of graphene is as high as $5300 \mathrm{~W} / \mathrm{m} \cdot \mathrm{K}$, which is higher than that of CNTs and diamond. The electronic mobility of graphene in room temperature exceeds $15000 \mathrm{~cm}^{2} /(\mathrm{V} \cdot \mathrm{s})$, which is higher than that of CNTs and silica crystals. As a result, the electrical resistivity of graphene is only about $10^{-6} \Omega \cdot \mathrm{cm}$, which is lower than that of copper and silver. Furthermore, graphine features high dielectric loss angle, which quantifies a dielectric material inherent dissipation of electromagnetic energy into heat.

Table 1 - Numbers of cement or typical OD nano fillers in $1 \mathrm{~cm}^{3}$ of cementitious composites

\begin{tabular}{|c|c|c|c|c|}
\hline Types & $\begin{array}{l}\text { Particle size } \\
(\mathrm{nm})\end{array}$ & $\begin{array}{l}\text { Volume of single } \\
\text { cement or nano particle } \\
\left(\mathrm{nm}^{3}\right)\end{array}$ & $\begin{array}{l}\text { Concentration } \\
\text { of nano fillers } \\
(\text { vol.\%) }\end{array}$ & $\begin{array}{l}\text { Numbers of cement or } \\
\text { nano particle in } \\
1 \mathrm{~cm}^{3} \text { of composites }\end{array}$ \\
\hline Cement & $10000-30000$ & $7.9 \times 10^{7}-7.1 \times 10^{8}$ & 0.1 & $1.4 \times 10^{9}-1.3 \times 10^{10}$ \\
\hline Nano-cement & 167 & $2.2 \times 10^{4}$ & 0.1 & $4.6 \times 10^{13}$ \\
\hline Nano-fly ash & $44.39-70.06$ & $1.5 \times 10^{3}-3.9 \times 10^{3}$ & 0.1 & $2.6 \times 10^{14}-6.5 \times 10^{14}$ \\
\hline NS & $10-40$ & $7.9 \times 10-1.3 \times 10^{3}$ & 0.1 & $8.0 \times 10^{14}-1.3 \times 10^{16}$ \\
\hline Nano- $\mathrm{CaCO}_{3}$ & $15-40$ & $1.8 \times 10^{2}-1.3 \times 10^{3}$ & 0.1 & $8.0 \times 10^{14}-5.7 \times 10^{15}$ \\
\hline Nano- $\mathrm{Al}_{2} \mathrm{O}_{3}$ & $10-150$ & $7.9 \times 10-1.8 \times 10^{4}$ & 0.1 & $5.7 \times 10^{13}-1.3 \times 10^{16}$ \\
\hline Nano- $\mathrm{TiO}_{2}$ & $15-21$ & $1.8 \times 10^{2}-3.5 \times 10^{2}$ & 0.1 & $2.9 \times 10^{15}-5.7 \times 10^{15}$ \\
\hline Nano- $\mathrm{Fe}_{2} \mathrm{O}_{3}$ & $20-60$ & $3.1 \times 10^{2}-2.8 \times 10^{3}$ & 0.1 & $3.5 \times 10^{14}-3.1 \times 10^{15}$ \\
\hline Nano- $\mathrm{Fe}_{3} \mathrm{O}_{4}$ & $4-7$ & $13-38$ & 0.1 & $2.6 \times 10^{16}-8.0 \times 10^{16}$ \\
\hline Nano-CuO & 15 & $1.8 \times 10^{2}$ & 0.1 & $5.7 \times 10^{15}$ \\
\hline Nano- $\mathrm{Cr}_{2} \mathrm{O}_{3}$ & 15 & $1.8 \times 10^{2}$ & 0.1 & $5.7 \times 10^{15}$ \\
\hline Nano- $\mathrm{ZnO}_{2}$ & 15 & $1.8 \times 10^{2}$ & 0.1 & $5.7 \times 10^{15}$ \\
\hline Nano- $\mathrm{ZrO}_{2}$ & 15 & $1.8 \times 10^{2}$ & 0.1 & $5.7 \times 10^{15}$ \\
\hline $\begin{array}{l}\text { Nano carbon } \\
\text { black }\end{array}$ & 30 & $7.1 \times 10^{2}$ & 0.1 & $1.4 \times 10^{15}$ \\
\hline
\end{tabular}

Table 2 - Numbers of typical 1D nano fillers in $1 \mathrm{~cm}^{3}$ of cementitious composites

\begin{tabular}{llllll}
\hline Types & $\begin{array}{l}\text { Diameter } \\
(\mathrm{nm})\end{array}$ & Length $(\mu \mathrm{m})$ & $\begin{array}{l}\text { Volume of single } \\
\text { nano particle }\left(\mathrm{nm}^{3}\right)\end{array}$ & $\begin{array}{l}\text { Concentration } \\
\text { of nano fillers } \\
(\text { vol.\%) }\end{array}$ & $\begin{array}{l}\text { Numbers of nano } \\
\text { particle in } \\
1 \mathrm{~cm}^{3} \text { of } \\
\text { composites }\end{array}$ \\
\hline SWCNTs & $0.75-3$ & $1-50$ & $8.0 \times 10^{2}-1.6 \times 10^{5}$ & 0.1 & $6.2 \times 10^{12}-1.2 \times 10^{15}$ \\
\hline
\end{tabular}




\begin{tabular}{llllll}
\hline MWCNTs & $2-30$ & $0.1-50$ & $3.1 \times 10^{2}-3.5 \times 10^{7}$ & 0.1 & $2.8 \times 11^{12}-3.2 \times 10^{15}$ \\
CNFs & $50-200$ & $50-100$ & $9.8 \times 10^{7}-3.1 \times 10^{9}$ & 0.1 & $3.2 \times 10^{8}-1.0 \times 10^{10}$ \\
\hline
\end{tabular}

Table 3 - Numbers of typical 2D nano fillers in $1 \mathrm{~cm}^{3}$ of cementitious composites

\begin{tabular}{llllll}
\hline Types & $\begin{array}{l}\text { Diameter } \\
(\mu \mathrm{m})\end{array}$ & $\begin{array}{l}\text { Thickness } \\
(\mathrm{nm})\end{array}$ & $\begin{array}{l}\text { Volume of single } \\
\text { nano particle }\left(\mathrm{nm}^{3}\right)\end{array}$ & $\begin{array}{l}\text { Concentration of } \\
\text { nano fillers } \\
(\text { vol.\% })\end{array}$ & $\begin{array}{l}\text { Numbers of nano } \\
\text { particle in } 1 \mathrm{~cm}^{3} \text { of } \\
\text { composites }\end{array}$ \\
\hline MLG & $<2$ & $1-5$ & $3.1 \times 10^{6}-1.6 \times 10^{7}$ & 0.1 & $6.4 \times 10^{10}-3.2 \times 10^{11}$ \\
\hline
\end{tabular}

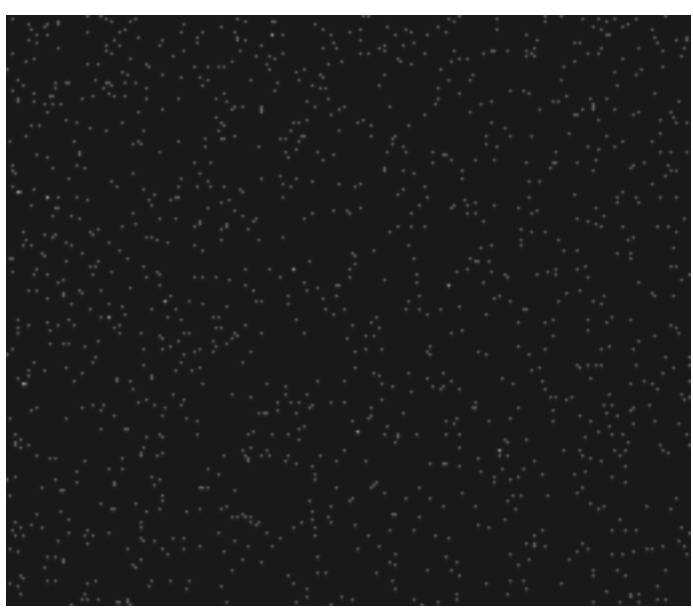

a) with $1 \%$ of Nano- $\mathrm{TiO}_{2}$

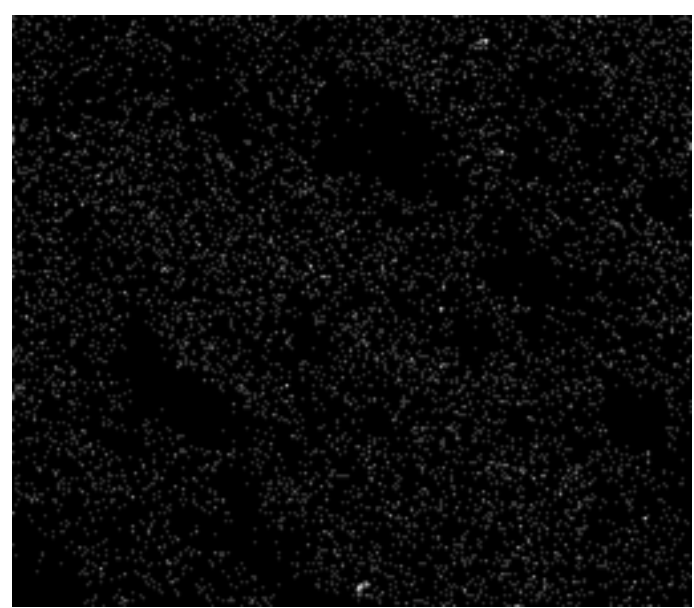

b) with $3 \%$ of Nano- $\mathrm{ZrO}_{2}$

Fig. 2 - SEM mapping images: a) Ti in cementitious composites with $1 \%$ of Nano- $\mathrm{TiO}_{2}(200 \times)$; b) $\mathrm{Zr}$ in cementitious composites with $3 \%$ of $\mathrm{Nano}-\mathrm{ZrO}_{2}$ $(200 x)$

\subsubsection{High surface area}

The surface area increases sharply with decreasing size of fillers. The specific surface area of typical cement and nano fillers is shown in Table 4. The surface area of nano fillers in Table 4 ranges from 10 to $1000 \mathrm{~m}^{2} / \mathrm{g}$, while the surface area of cement particle is only $0.28 \mathrm{~m}^{2} / \mathrm{g}$. The surface area of nano fillers is about 35-3571 times of that of cement particle. The higher filler surface area, the more atoms in surface. This means that nano fillers have higher surface energy compared with cement particle. Therefore, as shown in Fig. 3, the addition of nano fillers raises the system energy of cementitious composites, thus importing negative entropy to the system of composites. 
Table 4 - Specific surface area of typical cement and nano fillers

\begin{tabular}{|c|c|c|}
\hline Types & & Specific surface area $\left(\mathrm{m}^{2} / \mathrm{g}\right)$ \\
\hline Cement & & 0.28 \\
\hline \multirow{12}{*}{$\begin{array}{l}\text { OD } \\
\text { nano fillers }\end{array}$} & Nano-cement & 358.24 \\
\hline & NS & $50-345$ \\
\hline & Nano- $\mathrm{CaCO}_{3}$ & $24-32$ \\
\hline & Nano- $\mathrm{Al}_{2} \mathrm{O}_{3}$ & $10-180$ \\
\hline & Nano- $\mathrm{TiO}_{2}$ & $50-155$ \\
\hline & Nano- $\mathrm{Fe}_{2} \mathrm{O}_{3}$ & 60 \\
\hline & Nano- $\mathrm{ZnO}_{2}$ & 155 \\
\hline & Nano-CuO & 169 \\
\hline & Nano- $\mathrm{Cr}_{2} \mathrm{O}_{3}$ & 150 \\
\hline & Nano- $\mathrm{ZrO}_{2}$ & 160 \\
\hline & Nano carbon black & 254 \\
\hline & SWCNTs & $>690$ \\
\hline \multirow[t]{2}{*}{ 1D nano fillers } & MWCNTs & $>400$ \\
\hline & CNFs & 200 \\
\hline 2D nano fillers & NGP & $500-1000$ \\
\hline
\end{tabular}

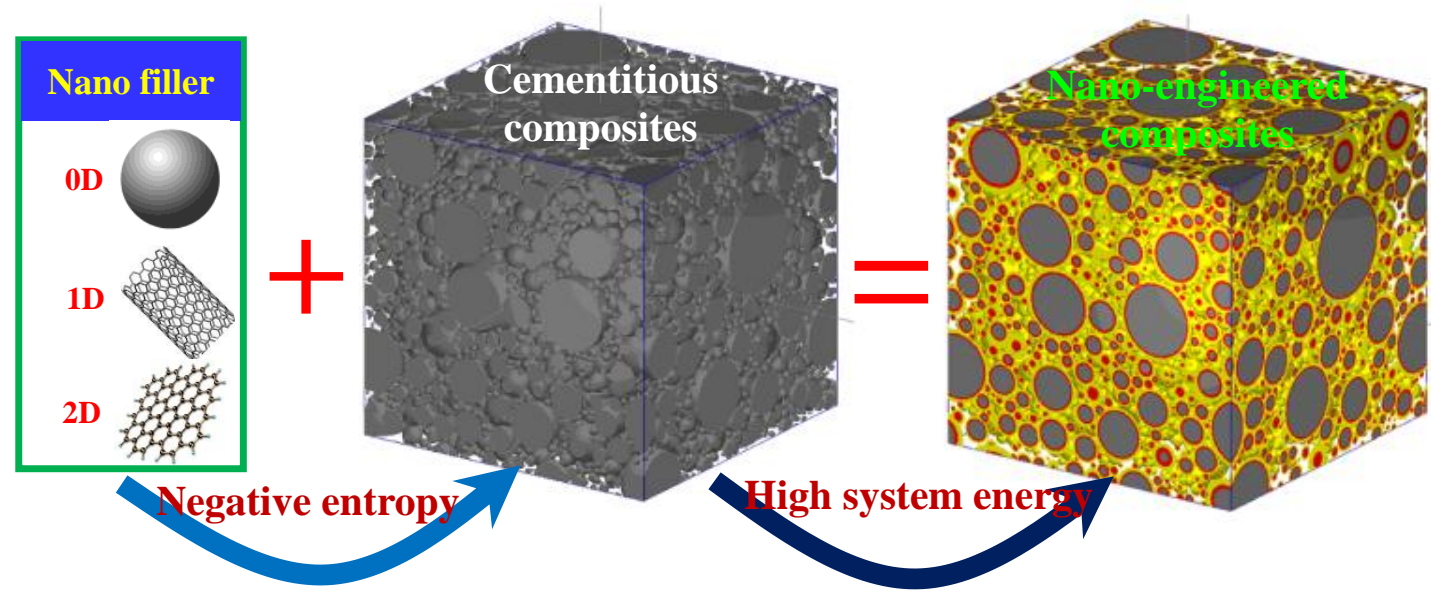

Fig. 3 - System of nano-engineered cementitious composites

\subsubsection{Core effect}

Core effect can be classified as intrinsic effect, nucleating effect, and filling or bonding effect.

\subsubsection{Intrinsic effect}

The intrinsic characteristics of nano fillers include their physical properties, chemical properties, morphology, and surface features. The intrinsic effects of nano fillers, which are beneficial to 
cementitious materials, are summarized in Table 5.

Table 5 - Classification of intrinsic effects of nano fillers

\begin{tabular}{|c|c|c|}
\hline \multicolumn{2}{|c|}{ Classification of intrinsic effects } & \multirow{2}{*}{ Benefit } \\
\hline Criteria & Categories & \\
\hline \multirow{6}{*}{$\begin{array}{l}\text { Mechanical } \\
\text { properties }\end{array}$} & Strength & \multirow{6}{*}{$\begin{array}{l}\text { Enhance mechanical properties of composites for } \\
\text { fillers with high mechanical properties }\end{array}$} \\
\hline & Modulus & \\
\hline & Hardness & \\
\hline & Toughness & \\
\hline & Damping & \\
\hline & Wear resistance & \\
\hline \multirow{3}{*}{$\begin{array}{l}\text { Electrical } \\
\text { properties }\end{array}$} & Electrically conductive & Improve electrical conductivity of composites \\
\hline & Electrothermal & Endow self-heating capability with composites \\
\hline & Electromechanical & Attach sensing capability to composites \\
\hline \multirow{2}{*}{$\begin{array}{l}\text { Thermal } \\
\text { properties }\end{array}$} & Thermally conductivity & \multirow{2}{*}{$\begin{array}{l}\text { Increase thermal conductivity and decrease } \\
\text { capacity of composites }\end{array}$} \\
\hline & Specific heat & \\
\hline \multirow{2}{*}{$\begin{array}{l}\text { Electromagnetic } \\
\text { properties }\end{array}$} & Electromagnetic shielding & \multirow{2}{*}{$\begin{array}{l}\text { Endow electromagnetic shielding and absorbing } \\
\text { capability with composites }\end{array}$} \\
\hline & Electromagnetic absorbing & \\
\hline Density & & $\begin{array}{l}\text { Reduce filler mass dosage for fillers with low } \\
\text { density }\end{array}$ \\
\hline \multirow[b]{2}{*}{$\begin{array}{l}\text { Hydration } \\
\text { activity }\end{array}$} & Active & Participate in hydration reaction \\
\hline & $\begin{array}{l}\text { Pozzolanic or non } \\
\text { pozzolanic }\end{array}$ & $\begin{array}{l}\text { Participate in secondary hydration for pozzolanic } \\
\text { fillers }\end{array}$ \\
\hline \multicolumn{2}{|c|}{ Photocatalytic properties } & Attach photocatalytic capability to composites \\
\hline \multirow{5}{*}{ Morphology } & Diameter & $\begin{array}{l}\text { Increase filler number for fillers with small } \\
\text { diameter and enhance filed emission effect for the } \\
\text { fillers with small diameter }\end{array}$ \\
\hline & Length or width & $\begin{array}{l}\text { Increase connecting probability for fillers with big } \\
\text { length or width }\end{array}$ \\
\hline & Aspect ratio & $\begin{array}{l}\text { Enhance connecting probability for fillers with } \\
\text { high aspect ratio }\end{array}$ \\
\hline & Solid or hollow & Reduce filler mass dosage for hollow fillers \\
\hline & Single, few or multi layer & $\begin{array}{l}\text { Reduce filler mass dosage for single or few layer } \\
\text { fillers }\end{array}$ \\
\hline \multirow{4}{*}{ Surface features } & $\begin{array}{l}\text { Hydrophilic or } \\
\text { hydrophobic }\end{array}$ & $\begin{array}{l}\text { Improve filer dispersion for fillers with } \\
\text { hydrophilic surface }\end{array}$ \\
\hline & With functional group & $\begin{array}{l}\text { Improve filer dispersion and bond between filler } \\
\text { and matrix }\end{array}$ \\
\hline & Charged & Promote absorption and nucleating \\
\hline & Absorbable & $\begin{array}{l}\text { Promote nucleating, lower w/c ratio, or achieve } \\
\text { self-curing }\end{array}$ \\
\hline
\end{tabular}

The intrinsic effect mainly includes the following four aspects.

1) Accelerating hydration, refining hydration products and increasing gel compactness. Active or 
pozzolanic nano fillers with high surface energy can participate in hydration reaction and secondary hydration respectively, thus accelerating hydration progress of cmentitious composites. The pozzolan nano fillers can also consume $\mathrm{CH}$ crystal, generate C-S-H gel, and induce C-S-H gel moves toward needle-like and columnar. The above chemical reaction process also decreases the orientation of $\mathrm{CH}$ crystal and reduces the size of $\mathrm{CH}$ (as shown in Table 6 and Fig. 4) [27]. The non pozzolanic nano fillers can accelerate $\mathrm{C}-\mathrm{S}-\mathrm{H}$ gel formation due to increasing $\mathrm{CH}$ amount at the early age, prevent the $\mathrm{CH}$ and $\mathrm{AFt}$ crystal from forming big size, and modify the orientation index of CH crystal (as shown in Fig. 5, Table 7) [29, 30]. Therefore, the stiffness and hardness of C-S-H gel is improved and the structure flaw is lowered.

Table 6 - Cement hydration degree of cementitious composites with different fillers (\%)

\begin{tabular}{llllll}
\hline \multirow{2}{*}{ Type of composites } & \multicolumn{2}{l}{ With NS at curing age of 3d } & \multicolumn{2}{l}{ With CNFs at curing age of 28d } \\
& $0.0 \%$ & $0.5 \%$ & $2.0 \%$ & $0.0 \%$ & $0.6 \%$ \\
\hline Hydration degree & $61.1 \%$ & $65.2 \%$ & $70.6 \%$ & $65.9 \%$ & $70.1 \%$ \\
Standard deviation & $0.6 \%$ & $0.7 \%$ & $0.9 \%$ & $0.7 \%$ & $0.8 \%$ \\
\hline
\end{tabular}

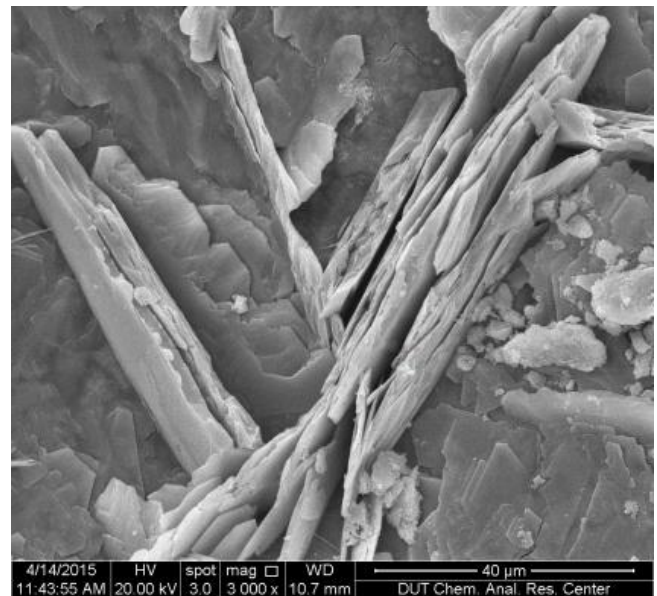

a) without NS

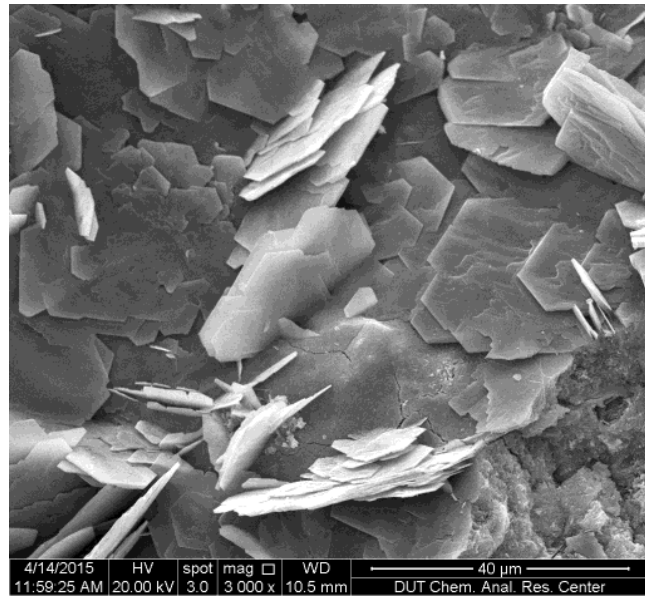

b) with $1.0 \%$ of NS

Fig. 4 - Comparison of SEM images of cementitious composites without and with NS 


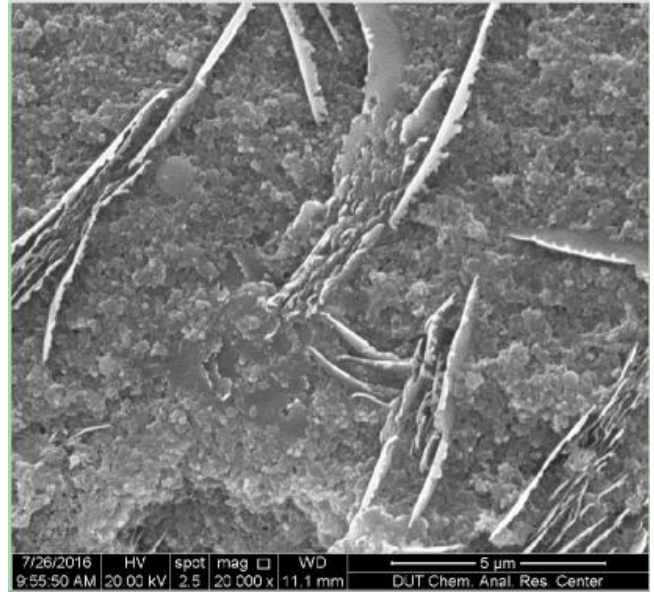

a) without nano- $\mathrm{TiO}_{2}$

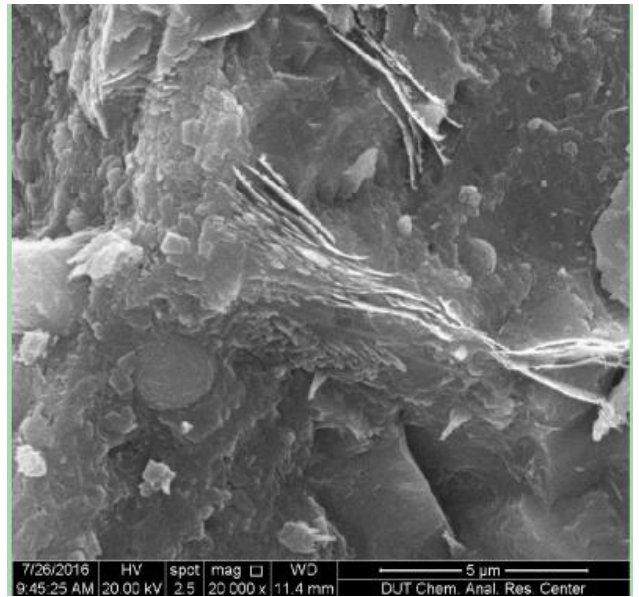

b) with $3.0 \%$ of nano- $\mathrm{TiO}_{2}$

Fig. 5 - Comparison of SEM images of cementitious composites without and with nano- $\mathrm{TiO}_{2}$

Table 7 - Comparison of orientation of $\mathrm{CH}$ inside cementitious composites with different nano fillers at curing age of $28 \mathrm{~d}$

\begin{tabular}{lllllll}
\hline \multirow{2}{*}{ Type of composites } & \multicolumn{2}{c}{ With NS } & \multicolumn{2}{c}{ With nano- $\mathrm{TiO}_{2}$} & \multicolumn{2}{c}{ With nano- $\mathrm{ZrO}_{2}$} \\
& $0 \%$ & $2.0 \%$ & $0 \%$ & $1.0 \%$ & $0 \%$ & $3.0 \%$ \\
\hline Orientation degree & 4.14 & 3.81 & 1.77 & 1.55 & 1.69 & 1.36 \\
Standard deviation & 0.11 & 0.09 & 0.06 & 0.04 & 0.06 & 0.04 \\
\hline
\end{tabular}

2) Adsorption. Due to big specific surface area and great surface energy, the nano fillers can serve as adsorption center of hydration product, water and ion. The adsorption of hydration product can accelerate the hydration, increase the production and compactness of C-S-H gel. This can also decrease the aggregation and directional alignment of $\mathrm{CH}$ crystals, improving the strength and toughness of matrix. The water adsorption of numerous nano fillers with extensive distribution lowers the local ratio of water to binder in the cementitious composites inside the micro-zone surrounding each filler, and uniformly reduces ratio of water to binder inside total cementitious composites during early hydration. The water adsorbed by nano fillers will release from fillers during later hydration of cementitious composites. This is beneficial for the curing of cementitious composites (i.e. internal curing or self-curing), thus reducing the autogenous shrinkage. The adsorption of ion may accelerate nucleating, increase C-S-H gel aggregation, and compact the structure of matrix. 
3) Reducing primary crack. The nano fillers inhibit the growth of nanoscale flaws and fractures and provide a cement matrix essentially "crack free" due to the above motioned reasons. Meanwhile, the formation of nano-core decreases the primary cracks in the nanostructure. This is because some nano fillers with high thermal conduction (as shown in Table 8) can transfer hydration heat easily, thus decreasing the temperature stress and reducing the amount of heat cracking.

Table 8 - Comparison of thermal conductivity of cementitious composites without and with MLG at curing age of $28 \mathrm{~d}$

\begin{tabular}{lll}
\hline Composites & Without MLG & With 1\% of MLG \\
\hline Thermal conductivity $(\mathrm{W} /(\mathrm{m} \cdot \mathrm{K}))$ & 1.10 & 1.22 \\
Standard deviation & 0.01 & 0.02 \\
\hline
\end{tabular}

4) Functional effect. Thanks to unique electrical, thermal, electromagnetic, sensing, and photocatalytic behaviors of nano fillers, functional, multifunctional or smart characteristics of cementitious composites can be enhanced or produced by adding nano fillers $[4,16,17]$.

\subsubsection{Nucleating effect}

Due to great surface energy of nano fillers, the hydration production will deposit on the fillers that distribute in cementitious materials. The nano fillers just like 'nucleus' which are surrounded by the hydration production. According to chemical activity, nano fillers which can react with components from the pore solution of cement called active nano fillers and the others called inert nano fillers. Nucleating effect is different for the two kinds of nano fillers. Inert nano fillers may act as a nucleation site by themselves. However, active nano fillers may first react with components of cement then the products act as nucleation site [31, 32]. The models to describe the filler effect on cement hydration distinguish between two kinds of nano fillers are shown in Fig. 6. Fig. 6 a), b) and c) show the hydration of pure cement, the cementitious composites with inert nano fillers, and the cementitious composites with active nano fillers, respectively. Due to nucleation sites offered by nano fillers, the time consuming nucleation reactions can be saved and dormant period of cement hydration can be shortened $[33,34]$. Therefore, the hydration process can be accelerated. It also can 
be seen from Fig.6 that nano fillers act as nucleation sites in pore solution. Hydration products can form not only around the cement particles but also around nano fillers in pore solution. That leads to more uniformly distribution of hydration products and a denser matrix. What's more, nano fillers also have effect on the structure and morphology of C-S-H. The fraction of high stiffness C-S-H gel in the pastes increased, which is determined by nano indentation techniques as NS was added to cementitious materials [35].

a)

b)

c)

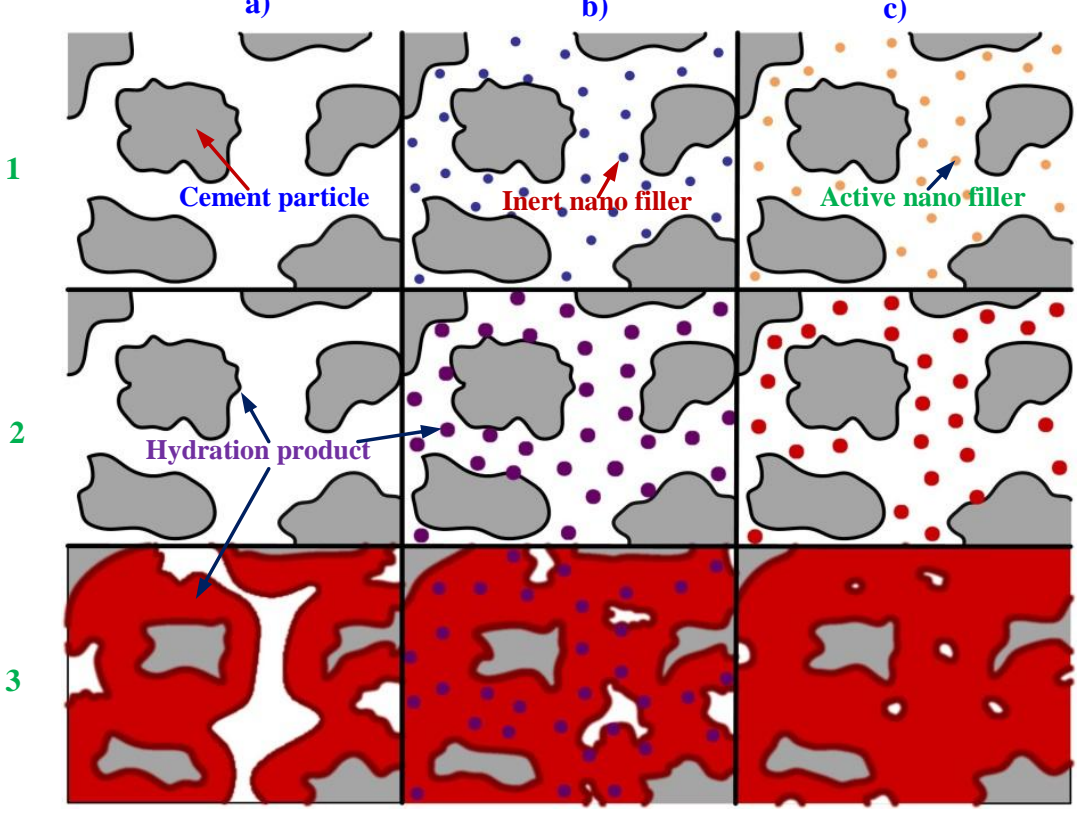

Fig. 6 - Hydration of pure cement a), with inert nano fillers b) and with active nano fillers c)

\subsubsection{Filling or bonding effect}

Hardened cementitious composites contain numerous and multiscale pores in nature. The nano fillers with small size can fill these pores, thus optimizing pore structures, lowering the porosity and improving the compactness [35]. For example, the CNT/CNF-core fines pore size distribution and decreases the porosity (or nanoporosity) of composites by filling the gaps (or pores) between the hydration products such as C-S-H gel and AFt [18, 36, 37]. 
In addition, there exists bonding effect in the cementitious composites with nano fillers. The bonding between nano fillers and cementitious matrix can be physical or/and chemical, which generates such enhancing effect as crack bridging, crack deflection and pinning (as shown in Fig. 7). A large amount of nano fillers are anchored inside the hydration products and across flaws and cracks. When the cracks in the matrix encountered well-distributed nano-core, the pinning effect and the efficient crack bridging can inhibit the crack growth at the very preliminary stage of crack propagation within the composites [38, 39]. The nano fillers also divert crack energy into a matrix to inhibit cracks propagation and make cracks deflection. The bridge coupling effect of nano fillers guarantees the load-transfer across voids and cracks [15]. This enhancement effects result from the energy release caused by these reinforcing behaviors. It should be noted that the bonding effect can be enhanced through the surface modification of nano fillers. Peyvandi et al. employed hydrophilic groups (-COOH) covalence-modified CNF to improve interfacial interactions in composites, in which the $-\mathrm{COOH}$ groups form strong coordinate bonds with the $\mathrm{Ca}^{2+}$ ions in cement hydrates, thus enhancing the mechanical properties of composites [40].

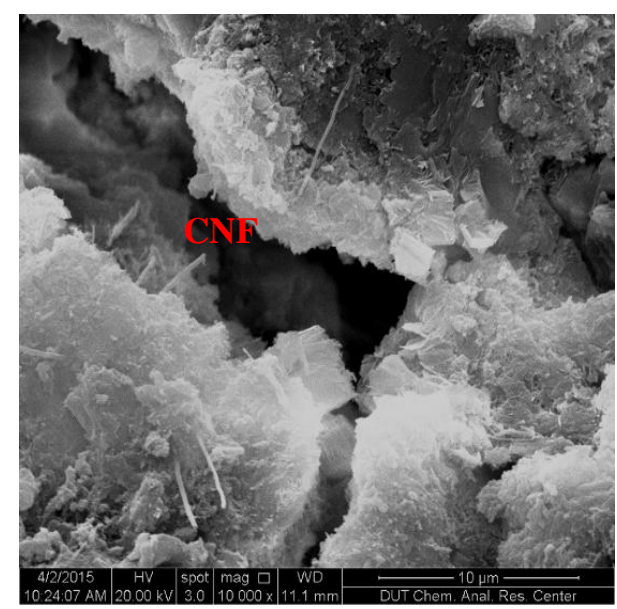

a) with $0.15 \%$ of $\mathrm{CNF}$

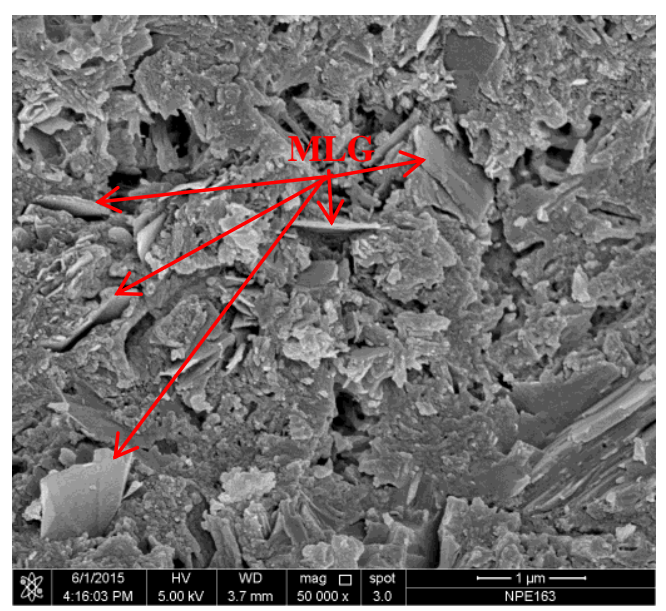

b) with $2 \%$ of MLG

Fig. 7 - SEM images of cementitious composites with nano fillers

\subsection{Factors affecting nano-core effect}

The nano-core effect is mainly governed by the intrinsic properties of nano fillers, and also is 
affected by composition of the cementitious composites and dispersion of nano fillers. These factors control the nano-core nature, number and distribution in the composites.

3.2.1 The intrinsic properties of nano filler play an important role in nano-core effect Up to date, nano fillers with different nature (including nano nonmetallic oxides, nano metallic oxides, nano carbon materials and other nano materials) have been incorporated into cementitious composites. Because NS has high pozzolanic activity, the resulting nano-core can participate in hydration reaction $[26,41]$. Due to excellent hardness, stiffness and toughness of $\mathrm{Nano}-\mathrm{Al}_{2} \mathrm{O}_{3}$, nano- $\mathrm{TiO}_{2}$ and nano- $\mathrm{ZrO}_{2}$, the resulting nano-core is strong and tough. The nano carbon materials including CNTs, CNFs, and MLG all have excellent electrical, thermal and electromagnetic properties. As a result, the resulting nano-core can form not only load-transfer chain but also electrical conductive pathway, providing multifunctional/smart ability to cementitious composites $[18,42-45]$. Additionally, the thermal conductivity of cementitious composites decreases and the resistance thermal distortion increases because of the presence of carbon nano-core [46, 47]. Meanwhile, the carbon nano-core makes the cementitious composites have electromagnetic interference shielding or adsorbing properties [48]. The nano-core constituted of nano carbon materials containing oxygen and nitrogen groups in chemical structure can enhance the bond between fillers and matrix, and presents high adsorption capability to water or ion. Commonly, 0D nano particles are easier to disperse into the composite, compared with 1D nano fibers and 2D nano plates, leading to that the amount of nano-core constituted of nano particles is more than that constituted of 1D nano fibers and 2D nano plates in cementitious matrix at the same filler content. However, the spatial size effect of nano-core constituted of $1 \mathrm{D}$ nano fibers and 2D nano plates is superior to that of nano-core constituted of OD nano particles because 1D or 2D filler processes the long range advantage in specific direction against OD nano particles. In addition, for the same fillers at the same content level, the nano filler in hollow and signal/few 
wall/layer form can generate larger nano-core number than that in solid and multi wall/layer form. 3.2.2 The nano-core effect is closely related to the raw materials and the mix proportion of cementitious composites

The higher nano filler content will lead the larger the number of nano core if the nano filler dispersion issue is not considered. The water-binder ratio is another most sensitive factor that influences the nano-core effect among mix proportion. This is because that commonly nano filler needs to be first dispersed in water for being conveniently and effectively incorporated into cementitious matrix. The water-binder ratio determines amount of water and nano filler concentration in aqueous solution, thus affecting the number and distribution of nano-cores. In addition, the type and amount of cement, aggregate and admixture, especially for cement, mineral and chemical admixture, can also change the number and distribution of nano-core.

\subsubsection{The nano-core effect obviously depends on the dispersion of nano fillers}

Because the strong Van der Waals forces cause the agglomeration of the nano fillers, the dispersion of nano fillers in cementitious matrix dominates the number and distribution of nano-cores. The poor dispersion of the nano fillers will limit the nano-core effect. Therefore, the specific processing technology is needed to achieve effective dispersion of nano fillers in cementitious matrix. In fact, the above-mentioned factors may work together for contribution to nano-core effect, but only one or several of them are leading for certain type of nano fillers.

\subsection{Nano-core effect zone}

As shown in Fig. 8, because the nano-core is tiny, it only has impact on the cementitious matrix arrounding nano-core in short range that forms a shell. This shell is a transition zone, which is different from cementitious matrix in long range. Therefore, a nano-core-shell element represents a nano-core effect zone. The characteristics of each nano-core-shell element, which include properties (e.g. mechanical property, durability, electrical property, thermal property and electromagnetic 
property) and structures (e.g. core size, shell size, ratio of core to shell, and spatial distribution gradient), are governed by the nano-core effect. However, the relationship between nano-core-shell elements depends on the number and distribution of each nano-core-shell element. It can be seen from Fig. 8 that $d$ (i.e. the separation between nano-core-shell elements) should be less than or equal to zero in order to implement nano-core effect inside the whole composites. This can be proved from that the modifying effect of nano fillers to cementitious composites is enhanced with nano filler content increase if the nano filler dispersion issue is not considered.

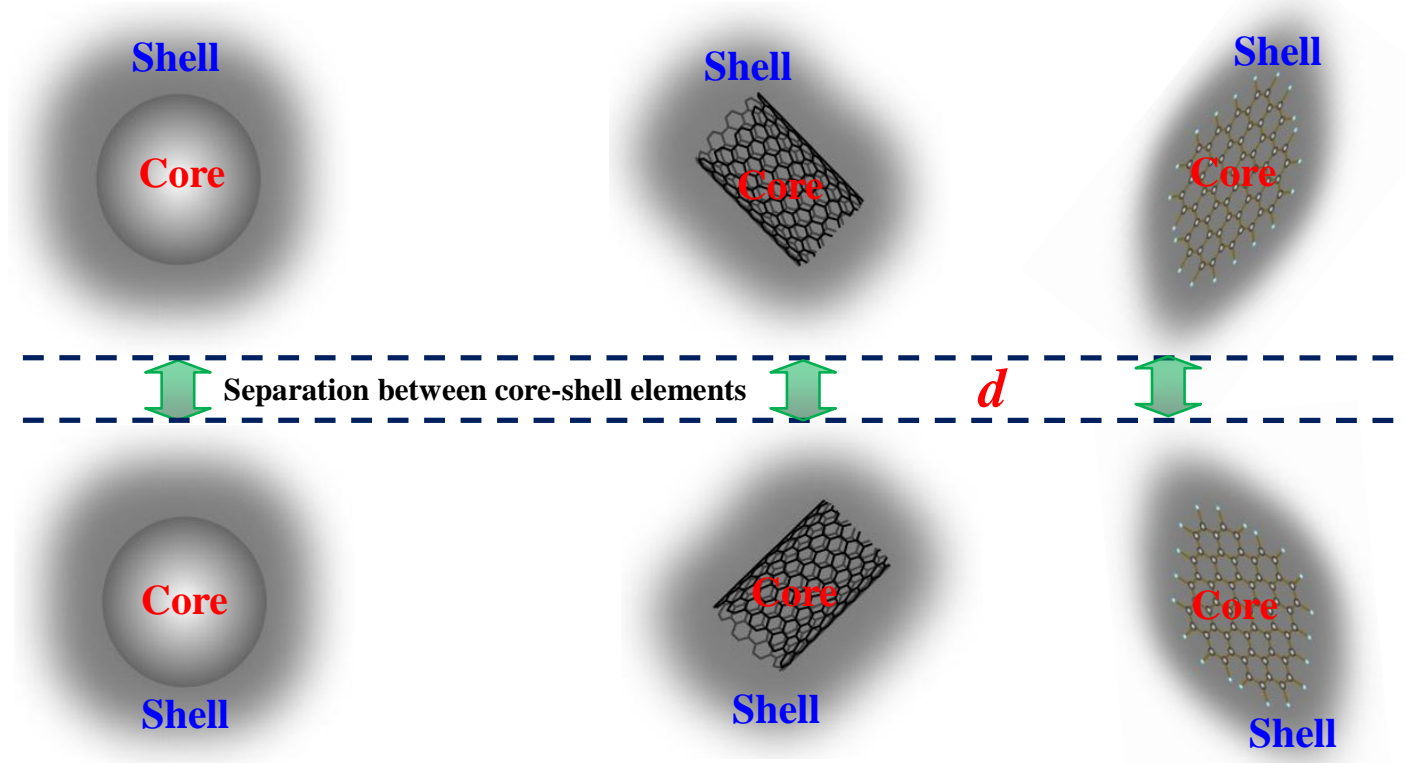
Fig. 8 - Diagram of relationship between nano-core-shell elements for 0D nano
particles, 1D nano fibers and 2D nano plates

Therefore, as shown in Fig. 9, the micro behaviors of cementitious composites with nano fillers can be described, predicted and designed through understanding and controlling the behaviors of nano-core-shell element in combination with the molecule dynamics simulation or multiscale/multiphysics modeling [21, 49-52].

\section{Conclusions}

Small can bring big change. Nanotechnology can make cementitious composites stronger, more 
durable and bring new multifunctional/smart properties. In this paper, the underlying mechanism of nano-engineered cementitious composites, i.e. nano-core effect was proposed and proved by experimental evidences. The nano-core effect can be attributed to the superposition of nano effect and core effect. Nano-effect mainly results from the small size and high surface area of nano fillers. Core effect originates in intrinsic effect, nucleating effect, and filling or bonding effect of nano fillers. The nano-core effect is closely relative to the intrinsic properties of nano fillers and composition and processing of the cementitious composites. The behaviors of the nano-engineered cementitious composites are controlled by nano-core effect zone, i.e. nano-core-shell element. The nano-core effect is fundamental for comprehensively understanding the genomic code of the nano-engineered cementitious composites in nature, featuring the blueprint to describe, predict, and control properties of the nano-engineered cementitious composites from nano-scale to micor-meso-macro-scale, and providing guide for design and fabrication of the nano-engineered cementitious composites. 


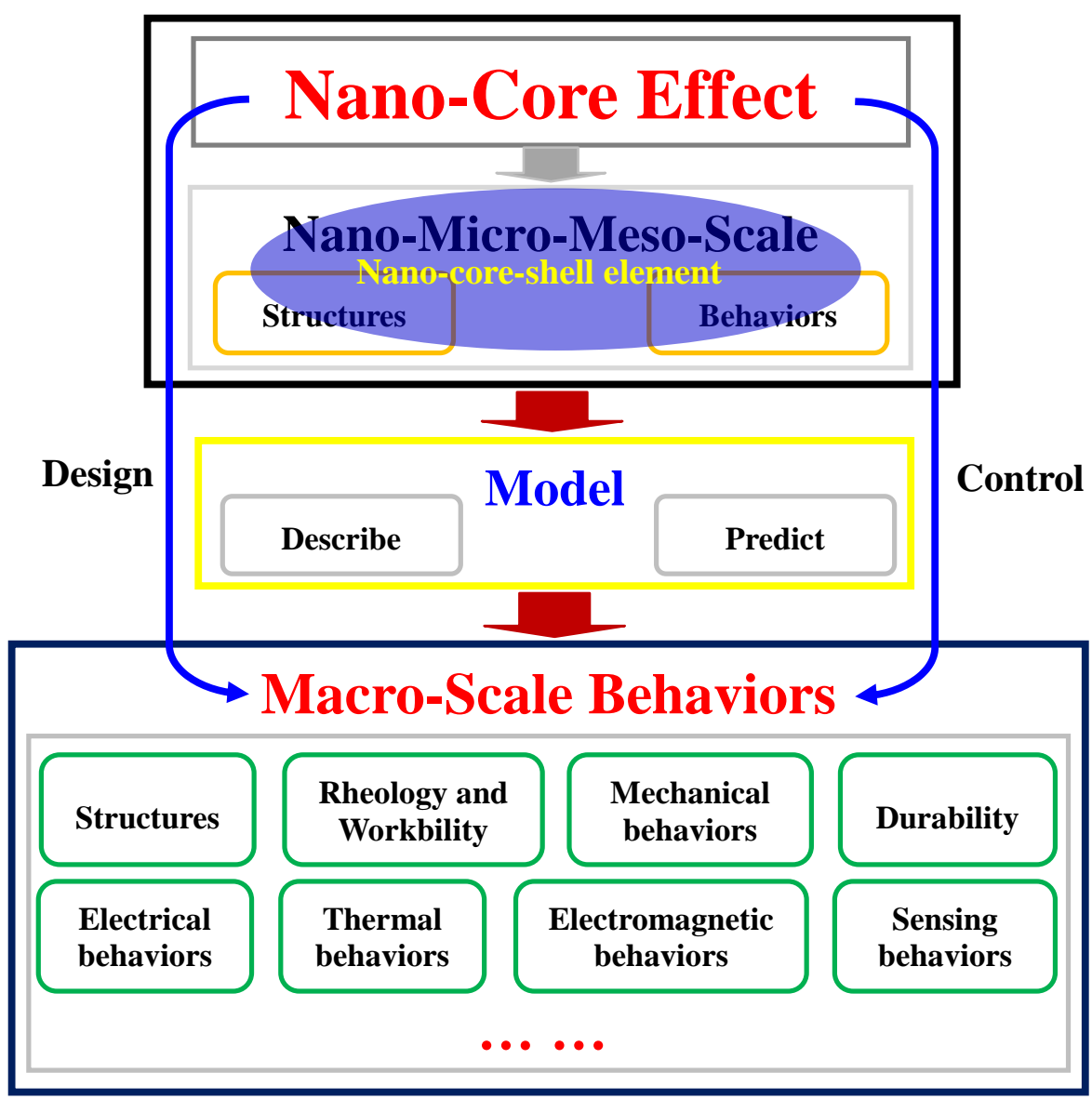

Fig. 9 - Nano-core effect engineered cementitious composites

\section{Acknowledgments}

The authors thank the funding supported from the National Science Foundation of China (51578110 and 51428801).

\section{References}

[1] Ma PC, Siddiqui NA, Marom G, Kim JK. Dispersion and functionalization of carbon nanotubes for polymer-based nanocomposites: a review. Compos Part A: Appl Sci Manuf 2010; 41(10):1345-67.

[2] Cui Y, Kundalwal SI, Kumar S. Gas barrier performance of graphene/polymer nanocomposites. Carbon 2016; 98: 313-333.

[3] Kim HK, Nam IW, Lee HK. Enhanced effect of carbon nanotube on mechanical and electrical properties of 
cement composites by incorporation of silica fume. Compos Struct 2014; 107: 60-69.

[4] Han B, Wang Y, Dong S, Zhang L, Ding S, Yu X, et al. Smart concretes and structures: A review. J Intel Mater Syst Struct 2015; 26 (11): 1303-1345.

[5] García-Macías E, D'Alessandro A, Castro-Triguero R, Pérez-Mira D, Ubertini F. Micromechanics modeling of the electrical conductivity of carbon nanotube cement-matrix composites. Compos Part B: Eng 2017; 108: 451-469.

[6] Zhang L, Ma N, Wang Y, Han B, Cui X, Yu X, et al. Study on the reinforcing mechanisms of nano silica to cement-based materials with theoretical calculation and experimental evidence. J Compos Mater 2016; 50 (29): 4135-4146.

[7] Shaikh FUA, Supit SWM, Sarker PK. A study on the effect of nano silica on compressive strength of high volume fly ash mortars and concretes. Mater Design 2014; 60: 433-442.

[8] Riahi S, Nazari A. Compressive strength and abrasion resistance of concrete containing $\mathrm{SiO}_{2}$ and $\mathrm{CuO}$ nanoparticles in different curing media. Sci China Technol Sci 2014; 54 (9): 2349-2357.

[9] Ibrahim RK, Hamid R, Taha MR. Fire resistance of high-volume fly ash mortars with nanosilica addition. Constr Build Mater 2012; 36: 779-786.

[10] Said AM, Zeidan MS, Bassuoni MT, Tian Y. Properties of concrete incorporating nano-silica. Constr Build Mater 2012; 36: 838-844.

[11] Chyad FA. The effects of metastable zirconia on the properties of ordinary Portland cement. Dissertation for the Doctoral Degree, University of Bradford, England, 1989.

[12] Sanchez F, Sobolev K. Nanotechnology in concrete -a review. Constr Build Mater 2010; 24 (11): 2060-2071.

[13] Chen J, Poon CS. Photocatalytic construction and building materials: From fundamentals to applications. Build Environ 2009; 44 (9): 1899-1906.

[14] Parveen S, Rana S, Fangueiro R. A review on nanomaterial dispersion, microstructure and mechanical properties of carbon nanotube and nanofiber reinforced cementitious composites. J Nanomater 2013; 71017580: $19 \mathrm{pp}$.

[15] Gupta S, Gonzalez J G, Loh KJ. Self-sensing concrete enabled by nano-engineered cement-aggregate interfaces. Struct Health Monitor 2016; DOI: 10.1177/1475921716643867

[16] Han B, Yu X, Ou J. Self-sensing concrete in smart structures. Elsevier; 2014. p. 385. 
[17] Han B, Sun S, Ding S, Zhang L, Yu X, Ou J. Review of nanocarbon-engineered multifunctional cementitious composites. Compos Part A: Appl Sci Manuf 2015; 70: 69-81.

[18] Han B., Yu X., Ou J. Multifunctional and smart carbon nanotube reinforced cement-based materials. Nanotechnology in civil infrastructure. Springer; 2011. p. 1-47.

[19] Han B, Yang Z, Shi X, Yu X. Transport properties of carbon-nanotube/cement composites. J Mater Eng Perform 2013; 22 (1): 184-189.

[20] Liew KM, Kai MF, Zhang LW. Mechanical and damping properties of CNT-reinforced cementitious composites. Compos Struct 2017; 160:81-88.

[21] Eftekhari M, Mohammadi S. Molecular dynamics simulation of the nonlinear behavior of the CNT-reinforced calcium silicate hydrate (C-S-H) composite. Compos Part A: Appl Sci Manuf 2016; 82:78-87. [22] Liew KM, Kai MF, Zhang LW. Carbon nanotube reinforced cementitious composites: An overview. Compos Part A: Appl Sci Manuf 2016; 91:301-323.

[23] Han B, Zhang L, Sun S, Yu X, Dong X, Wu T, et al. Electrostatic self-assembled carbon nanotube/nano carbon black composite fillers reinforced cement-based materials with multifunctionality. Compos Part A: Appl Sci Manuf 2015; 79: 103-115.

[24] Zhang L, Ding S, Sun S, Han B, Yu X, Ou J. Nano-scale behavior and nano-modification of cement and concrete material. Advanced Research on Nanotechnology for Civil Engineering Applications. IGI Global;2016. p. 28-79.

[25] Luo J, Duan Z, Xian G, Li Q, Zhao T. Damping performances of carbon nanotube reinforced cement composite. Mech Adv Mater Struct 2015; 22 (3): 224-232.

[26] Yu R, Spiesz P, Brouwers HJH. Effect of nano-silica on the hydration and microstructure development of Ultra-High Performance Concrete (UHPC) with a low binder amount. Constr Build Mater 2014; 65:140-150.

[27] Ye Q, Zhang Z, Kong D, Chen R. Influence of nano- $\mathrm{SiO}_{2}$ addition on properties of hardened cement paste as compared with silica fume. Constr Build Mater 2007; 21(3):539-545.

[28] Gupta SM, Tripathi M. A review of $\mathrm{TiO}_{2}$ nanoparticles. Chin Sci Bull 2011; 56 (16): 1639-1657.

[29] Jalal M, Ramezanianpour AA, Pool MK. Split tensile strength of binary blended self compacting concrete containing low volume fly ash and $\mathrm{TiO}_{2}$ nanoparticles. Compos Part B: Eng 2013; 55: 324-337.

[30] Meng T, Yu Y, Qian X, Zhan S, Qian K. Effect of nano- $\mathrm{TiO}_{2}$ on the mechanical properties of cement mortar. 
Constr Build Mater 2012; 29: 241-245.

[31] Thomas JJ, Jennings HM, Chen JJ. Influence of nucleation seeding on the hydration mechanisms of tricalcium silicate and cement. J Phys Chem C 2009; 113(11): 4327-4334.

[32] Land G, Stephan D. Controlling cement hydration with nanoparticles. Cem Concr Compos 2015; 57: 64-67.

[33] Mondal P, Shah SP, Marks LD, Gaitero JJ. Comparative study of the effects of microsilica and nanosilica in concrete. Transport Res Record: J Transport Res Board 2010; 2141: 6-9.

[34] Gaitero JJ, Campillo I, Mondal P, Shah SP. Small changes can make a great difference. Transport Res Record: J Transport Res Board 2010; 2141: 1-5.

[35] Gaitero JJ, Campillo I, Guerrero A. Reduction of the calcium leaching rate of cement paste by addition of silica nanoparticles. Cem Concr Res 2008; 38 (8): 1112-1118.

[36] Liew KM, Kai MF, Zhang LW. Carbon nanotube reinforced cementitious composites: An overview. Compos Part A: Appl Sci Manuf 2016; 91:301-323.

[37] Nochaiya T, Chaipanich A. Behavior of multi-walled carbon nanotubes on the porosity and microstructure of cement-based materials. Appl Surf Sci 2011; 257 (6) : 1941-1945.

[38] Makar JM, Margeson JC, Luh J. Carbon nanotube/cement composites-early results and potential applications. In: Proceedings of the 3rd International Conference on Construction Materials: Performance, Innovations and Structural Implications, Vancouver, Canada, 2005. p. 1-10.

[39] Nasibulin AG, Shandakov SD, Nasibulina LI, Cwirzen A, Mudimela PR, Habermehl-Cwirzen K, et al. A novel cement-based hybrid material. New J Phys 2009; 11 (2): 023013.

[40] Peyvandi A, Sbia LA, Soroushian P, Sobolev K. Effect of the cementitious paste density on the performance efficiency of carbon nanofiber in concrete nanocomposite. Constr Build Mater 2013; 48: 265-269.

[41] Ghafari E, Costa H, Júlio E, Portugal A, Durães L. The effect of nanosilica addition on flowability, strength and transport properties of ultra high performance concrete. Mater Des 2014; 59: 1-9.

[42] Han B, Yu X, Kwon E. A self-sensing carbon nanotube/cement composite for traffic monitoring. Nanotechnology 2009; 20 (44) : 445501.

[43] Han B, Ding S, Yu X. Intrinsic self-sensing concrete and structures: A review. Measurement 2015; 59: 110-128.

[44] Materazzi AL, Ubertini F, Alessandro AD Carbon nanotube cement-based transducers for dynamic sensing 
of strain. Cem Concr Compos 2013; 37: 2-11.

[45] Han B, Zhang K, Yu X, Kwon E, Ou J. Electrical characteristics and pressure-sensitive response measurements of carboxyl MWNT/cement composites. Cem Concr Compos 2012; 34 (6) : 794-800.

[46] Yakovlev G, Kerienè J, Gailius A, Girnienè I. Cement based foam concrete reinforced by carbon nanotubes. Mater Sci 2006; 12 (2): 147-151.

[47] Kerienė J, Kligys M, Laukaitis A, Yakovlev G, Špokauskas A, Aleknevičius M. The influence of multi-walled carbon nanotubes additive on properties of non-autoclaved and autoclaved aerated concretes. Constr Build Mater 2013; 49 : 527-535.

[48] Singh AP, Mishra M, Chandra A, Dhawan SK. Graphene oxide/ferrofluid/cement composites for electromagnetic interference shielding application. Nanotechnology 2011; 22 (46): 465701.

[49] Yang RW, Qiang G, Lemarchand E, Fen-Chong T, Li KF. Micromechanical modeling of transport properties of cement-based composites: Role of interfacial transition zone and air voids. Transp Porous Media 2015;110 (3): 591-611.

[50] Michopolulos JG, Farhat C, Fish J. Modeling and simulation of multiphysics systems. Transactions of the ASME 2005; 5: 198-213.

[51] de Borst R, Ramm E. Multiscale Methods in Computational Mechanics. Springer; 2011. p.445

[52] Ovrutsky AM, Prokhoda AS, Rasshchupkyna MS. Computational Materials Science: Surfaces, Interfaces, Crystallization. Elsevier; 2013. p388 